\title{
Design e Materiais: Análise sociotécnica e aplicação de novo material com minimização de recursos em Conceição dos Ouros, MG
}

\section{Design and Materials: Socio-technical analysis and application of new material with minimization of resources in Conceição dos Ouros, MG}

\author{
Isabella B. G. Grego ${ }^{1}$, Maria Gabriela A. Ranieri¹ ${ }^{1}$, Adilson da S. Mello ${ }^{1}$, Érik Leonel Luciano²,
} Bianca Siqueira Martins Domingos ${ }^{3}$, Rosinei Batista Ribeiro ${ }^{1}{ }^{2}$

\begin{abstract}
RESUMO
Esta pesquisa visa a incorporação de um resíduo proveniente da produção cervejeira como meio de minimização de matéria prima utilizada para fabricação de imagens sacras em gesso, bem como o direcionamento desse resíduo para uma utilização viável de reuso. A pesquisa em questão trabalha com uma empresa familiar de pequeno porte, que utiliza de técnicas empíricas para fabricação de placas de gesso no município de Conceição dos Ouros, localizada no sul do estado de Minas Gerais. As técnicas utilizadas para desenvolvimento do projeto vão desde a observação e mapeamento em campo até as análises laboratoriais das matérias primas utilizadas para produção dos artefatos tais como: microscopia eletrônica de varredura, testes de absorção de água e análise termogravimétrica. Em resultados obtidos foi possível observar como o grupo está organizado e aberto para colaborar na implementação de uma nova tecnologia, no caso o compósito, sem descartar as questões sociais, culturais e econômicas do município e da empresa estudada.
\end{abstract}

Palavras-chave: Design; Interdisciplinaridade; Novos Materiais; Gesso; Terras de diatomáceas.

\begin{abstract}
This research aims to incorporate a residue from beer production as a way to minimize the raw material used for making sacred images in plaster, as well as directing this residue for a viable reuse. The research in question serves a small family business that uses empirical techniques to manufacture plasterboard in the municipality of Conceição dos Ouros, located in the south of the state of Minas Gerais. The techniques used to develop the project range from field observation and mapping to laboratory analysis of the raw materials used in the production of artifacts such as: scanning electron microscopy, water absorption tests and thermogravimetric analysis. In the results obtained, it was possible to observe how the group is organized and open to collaborate in the implementation of a new technology, in this case the composite, without discarding the social, cultural and economic issues of the studied municipality and company.
\end{abstract}

Keywords: Design; Interdisciplinarity; New Materials; Plaster; Diatomaceous earth.

1Programa de Pós-Graduação em Desenvolvimento, Tecnologia e Sociedade, Instituto de Engenharia de Produção e Gestão, Universidade Federal de Itajubá, campus de Itajubá, Minas Gerais, Brasil.

*Email: rosinei1971@gmaill.com

2Programa de Pós-Graduação em Gestão e Tecnologia em Sistemas Produtivos - Unidade de Pós-Graduação, Extensão e Pesquisa - Centro Estadual de Educação Tecnológica Paula Souza CEETEPS - São Paulo, Brasil.

${ }^{3}$ Programa de Pós-Graduação em Planejamento Urbano e Regional - Universidade do Vale do Paraíba - UNIVAP, São José dos Campos, São Paulo, Brasil. 


\section{INTRODUÇÃO}

Nos últimos anos, os danos ao meio ambiente causados pelo descarte de resíduos industriais têm gerado grandes preocupações no Brasil e no mundo. As leis ambientais brasileiras tornaram-se muito mais severas e a fiscalização mais eficiente. Além disso, o custo para uma indústria construir aterros sanitários para descartar legalmente seus resíduos é extremamente alto. Esses dois problemas têm despertado muito interesse em buscar alternativas para utilizar resíduos industriais criando novos materiais. Esse estudo foi motivado principalmente pela questão da proximidade da universidade com diversas fábricas de placas de gesso para acabamentos decorativos e uma indústria cervejeira.

A grande produção de placas de gesso levanta questionamentos acerca do uso excessivo de recursos não renováveis, o gesso e a água. Além disso, destaca-se também a preocupação ambiental quanto ao descarte da terra de diatomáceas pela indústria cervejeira, material de origem orgânica que é utilizado no processo de filtragem da cerveja e que não possui um descarte adequado após seu uso. A proposta dessa pesquisa é substituir parte do gesso por este resíduo da produção cervejeira na produção de placas. Essa ideia colaboraria com a redução dos resíduos utilizados pelas cervejarias e também, poderá reduzir o uso de matéria prima natural.

Em relação à produção de cerveja, o Brasil se encontra em terceiro lugar no ranking de produção do mundo. Percorrendo por dados macros da Associação Brasileira da Indústria da Cerveja (CervBrasil), no ano de 2016 o país produziu 14 bilhões de litros de cerveja (CERVBRASIL, 2019). Essa produção implica diretamente na economia do país, correspondendo a 1,6\% do PIB nacional, movimentando 77 bilhões de faturamento em 2016 (CERVBRASIL, 2019). A larga demanda de produção de cerveja no país é determinante para desenvolvimento do novo compósito. Isso acontece porque as terras diatomáceas fazem parte do processo de clarificação e filtragem da cerveja, estando alocada em um dos estágios finais da produção. Após o processo, torna-se inviável a reutilização das terras de diatomácea como meio filtrante, porque o material fica saturado após sua primeira utilização. Portanto, a não utilização deste resíduo motiva o descarte inadequado do mesmo, o que contribui para preocupações a respeito das questões ambientais, impulsionando grandes e pequenas empresas por alternativas tecnológicas que retornem esse material a uma aplicação útil. 
A motivação para o planejamento de reuso deste resíduo se deu devido à identificação de duas principais necessidades: 1) a ausência de um destino adequado para o descarte desse material que é produzido em larga escala na indústria brasileira e, 2) a carência de melhorias no processo de produção de placas de gesso para minimização de recursos e consequentemente, redução do custo. Uma alternativa para, além de reduzir os impactos ambientais, contribuir com o desenvolvimento e crescimento de empresas familiares e em todo território nacional.

O desenvolvimento desta pesquisa possui como base teórico-metodológica os princípios interdisciplinares que possibilitam a discussão e aplicação da abordagem sociotécnica concomitante às competências do Design e da Engenharia de Materiais. Esse método amplia a exploração do desenvolvimento do compósito, considerando as questões contextuais do desenvolvimento dessa tecnologia no social.

A origem de oportunidade para o desenvolvimento de novos produtos é classificada por Baxter (2011) em duas vertentes: demanda de mercado e oferta de tecnologia. Para o autor, a demanda de mercado é reconhecida de duas maneiras, a primeira corresponde à necessidade da competitividade entre os produtos que exige a sua constante atualização e estratégias de mercado. A segunda é a necessidade de mercado que não pode ser atendida por nenhum produto já existente. A oferta de tecnologia, apresentada pelo autor e contemplada na pesquisa, refere-se à oportunidade de inovação do produto, disponibilizando novos meios de tecnologia, que pode ser contemplada em novos conceitos de projeto, novos processos de fabricação ou um novo material. (BAXTER, 2011).

Este novo material está associado ao meio em que será inserido, conectando valores locais sem grandes interferências no modo de fazer da empresa. Tem-se como proposta alinhar a comunidade em que está inserida, no caso as fábricas, o território, que tem sua dependência econômica atrelada direta e indiretamente à venda das placas, e o produto proposto, gerando assim qualidade e diferencial no serviço oferecido. Impulsionando o uso de uma nova tecnologia em um lugar/ambiente/cenário que já utiliza dos meios propostos de forma mais simplista (BAXTER, 2011).

Pensando Design associado às questões de inovação, Krucken (2009) ressalta a importância do designer e sua capacidade de reconhecer e conectar valores convertendoos em recursos mensuráveis em forma de inovação. Visto que sua pesquisa diz justamente 
da utilização dos meios que a comunidade oferece inserindo uma nova tecnologia, um diferencial, como estratégia de desenvolvimento local (KRUCKEN, 2009).

\subsection{Design e Interdisciplinaridade}

Jaspiassu (1994) define interdisciplinaridade como sendo um trabalho que se concretiza a partir da interação das disciplinas, que se amplia a partir da comunicação das ideias, integração de conceitos até a metodologia, os procedimentos, os dados e a organização da pesquisa. Raynaut (2011), por sua vez, aponta que o cenário atual de pesquisa tem a necessidade de recorrer a novos paradigmas, novas categorias de pensamento, novas metodologias de pesquisa e novas formas de ensino. Para Raynaut (2011) essas necessidades se conformam na interdisciplinaridade a partir das diferentes perspectivas disciplinares possíveis de serem incididas em um objeto de pesquisa (JASPIASSU, 1994; RAYNAUT, 2011).

Como consequência, para essa pesquisa, entende-se por interdisciplinaridade um campo que se constrói a partir das possibilidades de integração das disciplinas, seja por conceitos ou de maneira mais ampla, como na organização da pesquisa por meio de metodologias diversas. Essa integração gera uma nova perspectiva para compreender o objeto de pesquisa, que se desloca do campo disciplinar e se amplia para a relação entre esses campos do conhecimento.

A discussão levantada nesta pesquisa envolve três disciplinas distintas: Engenharia de Materiais, que se dá no desenvolvimento e análise de um novo compósito a partir de resíduos de produção de cerveja para a confecção de placas de gesso, Ciências Sociais através da análise sociotécnica intrínseca à ANT - por considerar a agência de atores humanos e não-humanos para melhor compreensão das características do campo. Essas características se apresentam quando a abordagem sociotécnica aponta os interesses concernentes à produção de placas de gesso, no âmbito macro dessa rede, e as questões inerentes às necessidades e interesses dos elementos humanos e não humanos presentes no âmbito micro dessa rede ao observar a realidade da empresa estudada. Por fim, a perspectiva do Design oferece a possibilidade de análise dos pontos relevantes do processo de produção das placas de gesso pela empresa, como a questão das etapas de mistura do gesso, do preenchimento dos moldes e das etapas de secagem e acabamento, além de outras características. 


\begin{abstract}
"O Design é uma atividade de contornos difusos e passiveis de interpretações variadas e bastante diferentes entre si. As definições de Design ora o apresentam como uma atividade cuja principal finalidade é a criação de produtos de valor estético, ora como importante promotor do desenvolvimento econômico, produtivo e tecnológico. Ora ressaltam sua importância para o aumento das vendas, manutenção e conquista de mercados, ora seu compromisso com a construção de um entorno ajustado às necessidades do ser humano, das mais básicas às mais transcendentais. Ora enfatizam o processo criativo, ora o produto em si, ora o indivíduo. Ora focam em quem produz, ora em quem compra, ora quem usa o produto. Ora inscrevem seu campo de conhecimento na esfera das Artes, ora no da Ciência, ora no da Tecnologia". (Couto (1996, apud DAMAZIO, 2005, p12).
\end{abstract}

De acordo com Cardoso (1998), o Design se configura como uma fonte relevante da cultura material de uma sociedade pela sua capacidade de transmissão de informação para além da linguagem falada e escrita. Além disso, o Design tem a capacidade de atuar em todas as etapas do processo de confecção de um artefato, desde o seu planejamento até sua finalização e distribuição (CARDOSO, 1998).

Ao pensar a prática do Design em países periféricos, como observa Bonsiepe (2012), é necessário o desenvolvimento de um modelo próprio de projeto, que minimize o uso de recursos, principalmente os energéticos, a fim de se alcançar um crescimento econômico. No caso da empresa, a criação desse novo material por meio de adição de terra de diatomáceas, aqui denominado GESSO TD, além do aproveitamento desse resíduo, há a possibilidade da redução de alguns recursos durante a preparação da matéria prima do artefato sem afetar seu aspecto estético e funcional.

Para Bonsiepe (2012), essa participação do Design em diferentes abordagens o torna ontologicamente interdisciplinar porque se preocupa com aspectos relacionados à “qualidade estética e de uso", mas também “às exigências técnicas-funcionais e restrições técnico-econômicas (BONSIEPE, 2012).

Bonsiepe (2012) acredita que, além de proporcionar satisfação e suprir algumas necessidades de consumo, cabe ao design oferecer às pessoas envolvidas no desenvolvimento do projeto a possibilidade de interação com o que está sendo trabalhado, ou seja, o design observa de forma mais abrangente e sistêmica todos os processos de elaboração e desenvolvimento do artefato, desde os aspectos técnicos até suas características mais subjetivas, como o conceito imbricado em determinado artefato (BONSIEPE, 2012).

Ainda assim, o design apresenta algumas possibilidades de exploração da interdisciplinaridade, por isso a necessidade de ampliar as disciplinas envolvidas no estudo, o que pode ser entendido aqui como o conceito de "colaboração" desenvolvido 
por Claude Raynaut. De acordo com Raynaut (2011), para que haja colaboração entre duas ou mais disciplinas de campos distintos - material e imaterial - é necessário definir o quadro referencial a partir do qual vão interagir as diferentes disciplinas. Desse modo, identificar os possíveis campos de observação para assim analisar como as propriedades estruturais e funcionais do objeto pesquisado se articulam, se combinam e se confrontam entre si.

Antes de qualquer coisa, espera-se que o designer industrial produza soluções novas para produtos industrializados. $\mathrm{O}$ designer industrial pode ser considerado como um produtor de ideias, recolhendo informação e utilizando-as na solução de problemas que lhe são apresentados. Além da capacidade intelectual, isto é, capacidade de reunir informações e utiliza-las em diversas situações, ele deve possuir capacidade criativa. A criatividade do designer industrial se manifesta quando baseando-se em seus conhecimentos e experiências, ele for capaz de associar determinadas informações com um problema, estabelecendo novas relações entre elas. Para isto é necessário observar fatos conhecidos sob novos pontos de vista, abandonando-se a segurança daquilo que é conhecido e comprovado, por uma postura crítica em busca de novas respostas e antigos problemas. A originalidade que se exige do designer industrial para conceber novos produtos inéditos deve-se ao imperativo cada vez maior da novidade como arma poderosa para superar situação competitiva de mercado (LOBACH, 2001).

Djon em prefácio de Krucken (2009) discorre sobre a importância da interferência do Design em todas as fases do processo produtivo e não só em seu desenvolvimento e aplicação por meio dos atributos plásticos e estéticos. Segundo o autor o fato dos designers conseguirem se relacionar em toda cadeia produtiva, ou seja, tanto os aspectos materiais e imateriais influem diretamente no aumento significativo de valor agregado no produto final. Essa interação com a rede que consiste em planejamento, desenvolvimento, distribuição, logística e comunicação com o mercado possibilita ao designer a facilidade de reconhecer e conectar valores convertendo-os em atributos mensuráveis, em forma de inovação (KRUCKEN, 2009).

Assim, congregando as concepções dos autores apresentados, é possível inferir que o Design possui a interdisciplinaridade como premissa tanto no campo teórico como no prático. Dessa maneira propõe-se que o Design não deva ser compreendido como uma ciência exata solucionadora de problemas direcionados, mas como a aproximação da 
realidade social por meio da projeção de mudanças necessárias que compreendam a existência de outras ciências como caminho de eficiência projetual.

\subsection{Abordagem Sociotécnica}

O Design e sua interdisciplinaridade intrínseca, como já citado na seção anterior, possibilitam diferentes abordagens e interpretações de um mesmo objeto dependendo do campo de estudo. As ciências sociais, assim como o Design, possuem diferentes correntes teóricas que possibilitam uma associação a outras ciências para o estudo de um mesmo objeto. Desta forma, em busca de uma perspectiva que incorpore tanto aspectos sociais quanto técnicos no desenvolvimento desta pesquisa, utilizou-se a incorporação da abordagem sociotécnica aliada à engenharia e ao Design para desenvolvimento de um novo compósito de gesso e terra de diatomáceas.

Valadão (2012) faz um breve relato dos sistemas sociotécnicos que tem suas origens das discussões na área de Administração, no século XX, em que "os estudos sobre trabalho tratavam de como adaptar seres humanos a funções e tarefas de produção e organização". Ainda segundo o autor, o conceito de sistema sociotécnico foi definido por um grupo de terapeutas, pesquisadores e consultores que desenvolveram uma técnica para que os soldados feridos em guerra pudessem reestruturar sua saúde psicológica e retomar a vida social. Acreditavam que essas técnicas poderiam contribuir na organização do trabalho industrial, este, que por sua condição desgastante para os trabalhadores, impediaos de desenvolvimento ou realização pessoal em decorrência do trabalho árduo diário exigido por seus superiores. Diante disso, em 1946, foi fundado o Instituto Tavistock de Relações Humanas, que tinha como intuito destacar a relação simétrica entre humanos e não humanos (máquinas, ferramentas e equipamentos de trabalho industrial) com a finalidade de "promover um programa que pudesse transformar a técnica e as condições sociais de trabalho de tal forma que a eficiência e a humanidade pudessem não estar em contradição uma com a outra".

No contexto do Instituto Tavistock, Trist e equipe e, posteriormente, Emery, definiram "a abordagem sociotécnica, também denominada teoria dos sistemas técnicos". Estes pioneiros acreditavam que seus projetos de pesquisa não deveriam ser apenas tentativas de aumentar o conhecimento, mas também de contemplar a melhoria de situações de trabalho que, até então, eram insatisfatórias em termos humanos Munford (2006), entendendo que a tecnologia não poderia ser o fator de controle quando novos 
sistemas de trabalho fossem implementados (MUNFORD, 2006; VALADÃO, 2012). A partir disso os estudos relacionados às análises e abordagens sociotécnicas se ampliaram possibilitando umm intercâmbio em diferentes áreas de estudo. A abordagem da dissociação do social e o técnico permite diferentes abordagens teóricas fundadas a partir de um aglomerado de um grupo, seja em seu grupo social ou em suas técnicas de manufaturas empíricas ou automatizadas. Vargens (2014) aborda em sua tese as principais correntes teóricas sociotécnicas, o que possibilita uma visão ampla de quais são as formas de abordagem e os diferentes meios de abordagens sociotécnicas. Para esta pesquisa, é relevante pontuar que a perspectiva sociotécnica é o método que considera os aspectos sociais que influenciaram na produção da tecnologia e o que essa, por sua vez, provoca na sociedade em contrapartida. Essa linha lógica já torna possível afirmar que a abordagem sociotécnica está de acordo com o princípio de simetria proposto por Latour (2012). Após observar a Tabela 1, é possível ampliar a visão sobre as possibilidades de abordagem teórica sociotécnica.

Tabela 1 - Correntes teóricas relacionadas abordagem sócio-técnica.

\begin{tabular}{|c|c|c|c|}
\hline Correntes & Conceito Principal & $\begin{array}{c}\text { Pesquisadores } \\
\text { Envolvidos }\end{array}$ & Exemplos de Pesquisa \\
\hline Autor-Rede & $\begin{array}{l}\text { Organização constituída } \\
\text { por relações que formam } \\
\text { laços a partir da agência } \\
\text { de humanos e não } \\
\text { humanos. }\end{array}$ & $\begin{array}{l}\text { - } \quad \text { Callon (1986) } \\
\text { - } \quad \text { Latour (1992) } \\
\text { Berg (1997) }\end{array}$ & $\begin{array}{l}\text { - } \quad \text { Redes de } \\
\text { conhecimento científico; } \\
\text { viagem. }\end{array}$ \\
\hline $\begin{array}{l}\text { Mangle of } \\
\text { Practice }\end{array}$ & $\begin{array}{l}\text { Agências humanas e } \\
\text { materiais são } \\
\text { temporalmente } \\
\text { emergentes na prática } \\
\text { diária. }\end{array}$ & $\begin{array}{ll}\bullet & \text { Pickering } \\
\text { (1995) } & \\
\bullet & \text { Jones (1998) }\end{array}$ & $\begin{array}{l}\text { • } \\
\text { de bolhas; } \\
\text { • } \quad \text { Introdução da câmara da } \\
\text { tecnologia de fabricação. }\end{array}$ \\
\hline $\begin{array}{l}\text { (Re) } \\
\text { configurações } \\
\text { Homem- } \\
\text { Máquina }\end{array}$ & $\begin{array}{l}\text { As fronteiras entre } \\
\text { pessoas e máquinas são } \\
\text { construídas } \\
\text { discursivamente e } \\
\text { materialmente }\end{array}$ & - Suchman (2007) & $\begin{array}{l}\text { - Serviços de } \\
\text { informação por Ciborgue; } \\
\text { • } \quad \text { Engenharia com } \\
\text { tecnologia de desenho } \\
\text { assistido por computador. }\end{array}$ \\
\hline $\begin{array}{l}\text { Formações } \\
\text { Digitais }\end{array}$ & $\begin{array}{l}\text { Estruturas Sociodigitais } \\
\text { que imbricam agentes } \\
\text { sociais e técnicas com } \\
\text { novas consequências. }\end{array}$ & $\begin{array}{l}\text { Latham \& } \\
\text { Sassen (2003) }\end{array}$ & $\begin{array}{l}\text { Mercados virtuais; } \\
\text { - Desenvolvimento de } \\
\text { software de código aberto; } \\
\text { - Redes sociais de } \\
\text { ativistas da sociedade civil. }\end{array}$ \\
\hline $\begin{array}{l}\text { Informação } \\
\text { Tecnológica }\end{array}$ & $\begin{array}{l}\text { Uma capitulação da } \\
\text { realidade à computação } \\
\text { que constitui as } \\
\text { organizações de várias } \\
\text { formas }\end{array}$ & - Kallinikos (2006) & $\begin{array}{l}\text { - } \quad \text { Fluxos de informação } \\
\text { em serviços financeiros e } \\
\text { empresas de mídia. }\end{array}$ \\
\hline $\begin{array}{l}\text { Configuração } \\
\text { Algorítmica }\end{array}$ & $\begin{array}{l}\text { Algoritmos de cálculos } \\
\text { que conformam as ações } \\
\text { de humanos e máquinas }\end{array}$ & $\begin{array}{ll} & \text { Callon \& } \\
\text { Muniesa } & (2005) \\
& \text { MacKenzie } \\
(2006) & \end{array}$ & $\begin{array}{l}\text { - Produção de preços } \\
\text { nos mercados brasileiros. }\end{array}$ \\
\hline
\end{tabular}


Fonte: Os Autores, 2021.

Levando em consideração o pressuposto de que as relações entre humanos e não humanos são simétricas e a relevância das ações de todos os envolvidos na rede apresentada pela Teoria Ator-Rede (LATOUR, 2012). Essa teoria consegue suprir as necessidades da pesquisadora no projeto, no qual se faz necessário o conhecimento das técnicas utilizadas pelos funcionários e suas relações da rede, em que está contextualizado o objeto de estudo proposto, o Gesso. O foco da abordagem, nesta pesquisa, não está na análise e avaliação minuciosa da rede para a posterior construção de mapas, mas sim na construção de uma base sólida para aproximar-se dos atores humanos e não humanos que podem, ou não, sofrer mudanças com a implementação do compósito desenvolvido durante a pesquisa.

A Teoria Ator-Rede (ou Actor-Network Theory) aqui referenciada pela sigla TAR, deriva da corrente epistemológica construtivista, compreendendo que o Social se forma a partir do agrupamento constante de novos elementos que contribuem para a realidade observada (DOSSE, 2003).

Nessa perspectiva, o Social é o agrupamento formatado em rede, no qual os elementos de sua composição estão atrelados a outros elementos, conforme disposto por Latour (2012). O conceito de rede pressupõe uma afetação entre os elementos componentes, no qual uma ação em um dos pontos dessa rede reverbera em um ou mais outros vértices da rede. A natureza desses elementos será referenciada como humanos e não humanos, assim como disposto na obra de Latour (2012). Na concepção em rede, a consideração de elementos humanos e não humanos como formadores do Social é um dos princípios sobre o qual se estrutura a TAR.

Ademais, não consiste também em compreender que os não humanos são meio ou ferramenta para os humanos atingirem seus objetivos, mas que são proporcionalmente ao contexto observado protagonistas que condicionam os arranjos desse Social (LATOUR, 2012). Esse protagonismo foi observado por Latour e Woolgar (1997) quando identificaram o que foi denominado "inscritor", ou seja, objetos que compõem um laboratório e que são essenciais para a realização da pesquisa, por exemplo, um microscópio, ou uma máquina centrífuga (LATOUR e WOOLGAR, 1997).

Considerando, portanto, a complexidade dos atores (humanos e não humanos) que conformam o Social-rede, a TAR compreende que as afetações entre esses atores nem sempre estão em concordância, ocorrendo de forma harmônica ou confluindo em mesmos 
vetores de ação. Assim, as ações e reações desses atores geram controvérsias. Segundo Law (1992), são nesses episódios controversos que o social "se movimenta", tomando novas formas de acordo com a disputa de forças entre os elementos agregados nesse contexto (LAW, 1992).

Law (1992) ainda afirma que as controvérsias direcionam o modo como o Social se organiza ao longo do tempo, complementando o que Latour (2012) afirma quanto ao caráter instável da rede, ou seja, o constante movimento desse Social decorrente do agregar e reagregar dos elementos que o compõem, que assim o fazem de acordo com seus interesses e com as forças de outros atores que o impelem a dessa forma agir. Latour (2012) desenvolve que essas forças e interesses são os aspectos que mudam as atribuições ou as ações dos atores na rede. Esse é o conceito de tradução, que em outras palavras, são os diferentes papéis que um ator pode desempenhar segundo os aspectos imateriais emanados por outros atores, independente de sua natureza.

A grande reformulação do pensamento acerca dos estudos sociais proposto pela TAR é a possibilidade de que novos métodos de pesquisa sejam desenvolvidos, já que a teoria oferece os princípios balizadores das metodologias possíveis e mais adequadas a cada tipo de pesquisa (LAW, 1992).

Thomas e Buch (2013) apresentam diversos métodos de pesquisa acerca da produção tecnológica, e a tecnologia, ontologicamente é um híbrido previsto pela TAR. Assim, a abordagem sociotécnica surge como um método de observação do campo que possui como parâmetros os princípios da TAR (THOMAS e BUCH,2013).

Sendo assim, Meyer (2015) identifica no design a possibilidade de atuação em colaboração com a teoria Ator-Rede (TAR) capaz de compreender a complexa relação humano e artefato. Entendendo que "Ator-Rede é radical uma vez que diz que estas redes são afetadas tanto por agentes humanos (designers, técnicos, usuários, clientes) como por agentes não humanos (tecnologia, prazos, negociações, normas)” (MEYER, 2015). O "Design-Rede" proposto por ele vai além das centralizações na técnica ou no humano. Propõe-se a mobilizar todos os aliados relacionados ao artefato, em uma operação que envolve o "convencimento, negociação e disputa de interesses" (MEYER, 2015).

Levando em conta a formação da pesquisadora e, principalmente, o potencial interdisciplinar do Design a pesquisa segue inspirada nas reflexões de Meyer no que diz respeito ao "Design-Rede". Vale enfatizar que esta pesquisa não tem como foco a análise da rede, mas sim, utilizar da TAR como base para a abordagem sociotécnica no lócus 
estudado. Como já citado, a ausência de uma metodologia rígida para a Teoria Ator-Rede a torna flexível e adaptável a conceitos e métodos o que, aliados a abordagem sociotécnica para visualizar a rede e sua complexidade de ações entre os humanos e não humanos estudados neste trabalho, a torna uma boa ferramenta para compreender o social e aproximar as técnicas empíricas estudadas, o lócus em sua "essência" e o laboratório institucional com seus padrões e normas. Essa aproximação se faz possível a partir da "lente" da TAR, que propõe uma abordagem completa de todos os elementos inerentes da rede.

\subsection{Design e Seleção de Materiais}

Desenvolvido a partir da perspectiva do design de produtos, o projeto vislumbra a combinação de elementos da ciência em prol da (re) criação de um produto de qualidade que atenda as demandas do mercado e crie impactos positivos na sociedade, através da minimização do impacto ambiental. Para Ashby e Johnson (2013), quando combinadas, materialidade e eficiência, permitem ao designer o desenvolvimento de um produto capaz de trazer inovação e novas expressões através de novas soluções visuais, táteis, esculturais e estruturais para o mercado. O desenvolvimento de novos materiais e propostas de criação são fatores que proporcionam maior inspiração aos designers de produtos (ASHBY e JOHNSON, 2013).

Cabe ao designer então, a partir de sua formação, a gestão projetual do processo em toda cadeia produtiva. Kindlein Jr e Guanabara (2006) ressaltam que o engenheiro trabalha com processos técnicos e econômicos acerca do produto final, realiza numerosos cálculos através dos softwares de simulação e recorre aos fundamentos teóricos e científicos em busca de uma "representação do produto através de parâmetros numéricos". Os autores apontam desta maneira que a competência do engenheiro neste processo está atrelada ao seu conhecimento em cálculos e sua "destreza” na utilização dos mesmos. Ashby e Johnson (2013) apontam que o design está atrelado aos aspectos que se referem ao correto funcionamento técnico de um produto, sua performance mecânica e térmica, ao seu custo e durabilidade. Reunidos, tais atributos podem ser chamados de atributos técnicos de um produto na descrição de seu funcionamento e performance (KIDLEIN Jr. e GUANABARA, 2006; ASHBY e JOHNSON, 2013). 
Com capacitações técnicas distintas, designers e engenheiros precisam buscar sintonia para o desenvolvimento de produtos que atendam às demandas tecnológicas, sociais e individuais de seus clientes, porém, Ashby e Johnson (2013) apontam que este diálogo é de grande complexidade:

\begin{abstract}
"Preencher essa lacuna de informações e métodos não é simples. Os termos técnicos usados por engenheiros não são a linguagem corrente dos designers industriais - na verdade, às vezes eles podem até achar que esses termos não têm sentido. Por outro lado, designers industriais expressam suas ideias e descrevem materiais de um modo que, para os engenheiros, às vezes parece qualitativo (ASHBY; JOHNSON, 2013 )."
\end{abstract}

Kindlein Jr. e Guanabara (2006) destacam que melhorar o diálogo entre os profissionais é imprescindível. Para os autores o engenheiro "deve ser aberto suficientemente de espírito para compreender um ponto de vista mais holístico [...] e o designer deve ser capaz de compreender os aspectos técnicos ligados aos materiais e processos de fabricação do produto". O conhecimento e as técnicas da Engenharia de Materiais, bem como as características dos materiais utilizados, são de extrema relevância para o desenvolvimento de um novo compósito. O material aqui proposto utiliza-se de resíduos da fabricação de cerveja (terra de diatomáceas) incorporados ao gesso, matéria prima já utilizada no processo de produção da empresa de artefato sacro estudada. (KIDLEIN Jr. e GUANABARA, 2006).

Callister (2012) define compósito como “qualquer material multifásico que exiba proporção significativa das propriedades de ambas as fases que constituem, de tal modo é obtida uma melhor combinação de propriedades". Diante disso entende-se como compósito um material que possui uma matriz e um reforço podendo ser a combinação de dois ou mais materiais que possuem propriedades físicas ou quimicamente distintas.

A produção de pequenas empresas muitas vezes não é capaz de competir no grande mercado de distribuição em massa que caracteriza o cenário atual. Krucken (2009) aponta alguns fatores que dificultam a sobrevivência dessas empresas no mercado, tendo destaque o modelo de custos inadequado, a padronização em massa dos produtos que acaba por desestimular as pequenas produções, a insatisfação dos clientes com a oferta limitada de produtos e sua autenticidade e também os altos custos ambientais provocados pela desregionalização e dessazonalização indiscriminadas.

Segundo a autora se faz necessária a inovação na intermediação de produtos locais através do "desenvolvimento de plataformas de serviços e infraestrutura que suportem modelos sustentáveis e vantajosos para os consumidores e produtores" (KRUCKEN, 2009). 
O material aqui proposto como aditivo ao gesso, as terra de diatomáceas são construídas essencialmente por carapaças de algumas diatomáceas, a diatomita é uma rocha rica em sílica de origem sedimentar. Diatomáceas são algas unicelulares com vida média de 24 horas e com uma alta capacidade de reprodução, sendo possível um indivíduo originar 100 milhões de descendentes em um período de 30 dias, seus tamanhos variam entre 5 e 400 micra (CIEMIL, 2015).

Para que as terra de diatomáceas sejam comercializadas, após a extração, o minério passa por um processo de perda de umidade e parte da matéria orgânica na própria jazida. Após esse processo, o minério é encaminhado para uma usina de beneficiamento na qual é submetido à calcinação em fornos rotativos à temperatura de $900{ }^{\circ} \mathrm{C}$. Com este procedimento todas as impurezas e contaminantes existentes no mineral são repelidas, em seguida é beneficiado e embalado para que seja destinado às indústrias em que seu maior forte de atuação é como agente filtrante, pois possui uma capacidade de retenção de material sólido, alta permeabilidade, e polimento do líquido filtrado, outra aplicação na qual merece destaque é sua utilização em defensivos agrícolas (CIEMIL, 2015).

O Departamento Nacional de Produção Mineral (DNPM) afirma em informações publicadas no último Sumário Mineral (2015) que o Brasil encontra-se entre os 10 maiores produtores de gipsita do mundo e é considerado o maior produtor de gesso da América do Sul. O consumo anual per capita do país é de aproximadamente $19 \mathrm{~kg}$ de gesso, deixando-o com uma média bem abaixo da média dos países industrializados. $\mathrm{O}$ gesso, material já utilizado pela empresa para a produção dos artefatos, provém da calcinação da gipsita, mineral encontrado em abundância na região nordeste do Brasil.

É um material de baixo custo e ampla utilização na indústria em geral, podendo ser encontrado na odontologia, medicina, engenharia civil, estátuas e afrescos, componentes industriais, dentre outros (DNPM, 2013).

\subsection{Lócus de Estudo}

Localizada no extremo sul de Minas Gerais a cidade de Conceição dos Ouros, com 10.388 habitantes (IBGE, 2010) e um território de 180,236 km² (IBGE, 2018) é considerada a maior produtora de placas e molduras decorativas de gesso do Sul de Minas. O município é banhado pelos rios Sapucaí-mirim e Capivari e pelo Ribeirão dos Ouros, que lhe dá o nome, e tem sua "vocação para a indústria" 
(https://www.conceicaodosouros.mg.gov.br/historia-de-conceicao-dos-ouros, acesso, 2019) reconhecida desde o século 19. O início da produção de gesso em Conceição dos Outros é datado de 1967 e atualmente a cidade conta com mais de 115 fábricas que produzem 150.000 placas por dia ou três milhões de placas por mês. De acordo com dados da prefeitura do município, as fábricas recebem mensalmente 15.000 toneladas de gesso vindos do Nordeste e a produção é vendida principalmente no estado de São Paulo e em cidades do Sul de Minas. https://www.conceicaodosouros.mg.gov.br/historia-deconceicao-dos-ouros, acesso, 2019).

O grande destaque do município na produção de placas de gesso fez com que este fosse o lócus escolhido para a o desenvolvimento da pesquisa. Foram visitadas quatro fábricas de placas de gesso, sendo que em apenas uma delas houve a possibilidade de desenvolver uma abordagem sociotécnica eficaz.

O responsável pela fábrica relatou que é uma empresa arrendada e conta com dois funcionários que recebem uma comissão sobre o que produzem e, por isso cada um dos produtores possui uma assinatura própria que é aplicada nas placas que produzem para que as comissões sejam contabilizadas. Ainda foi possível uma entrevista espontânea e muito rica para o aprofundamento da pesquisa no cenário.

Ele contou que alguns produtores do município costumam fazer experimentos com outros materiais, como casca de arroz e gesso moído, uma vez que é do interesse daqueles que produzem a redução de custos e uso de matéria-prima. Relatou que já fizeram alguns testes na fábrica, porém a dificuldade destas aplicações está na venda do produto, pois o consumidor final das placas é exigente e, mesmo que elas não sejam estruturais para uma construção e muitas vezes recebam camadas de tinta após serem aplicadas, o produto precisa apresentar um acabamento homogêneo e de alta brancura. Conta ainda que nenhum dos testes deu certo e que a casca de arroz, reduz o uso de matéria prima, porém aumenta a porosidade do produto, criando vazios superficiais no produto final e irregularidades no acabamento.

Ainda durante a visita o produtor pôde conhecer mais sobre a pesquisa e realizou seu primeiro contato com a terra de diatomáceas, o resíduo foi apresentado in natura e desidratado em laboratório. Após o seu descarte pela cervejaria, o resíduo foi adicionado ao gesso e assim, foram confeccionados corpos de prova com diferentes porcentagens de adição. Na concepção do produtor a terra de diatomácea foi, dentre todos os materiais que 
já experimentou adicionar, o que mais se assemelhou à estrutura in natura do gesso em textura e densidade. Sendo assim, a proposta dentro da empresa foi prontamente acolhida.

As visitas seguintes foram esporádicas e permitiram acompanhar e mapear o processo de produção, identificar ferramentas e modos de fazer para a etapa seguinte de produção de um protótipo dentro da fábrica.

Dentre todas as empresas abordadas e suas diferenças estruturais e também de acolhimento, a pesquisa constatou uma semelhança de extrema importância para o estudo. Essa realidade não possui diferença na técnica, que está incorporada no saber-fazer de cada funcionário. Todas as fábricas relataram o uso de quantidades próximas de gesso e água para a produção de uma placa moldada de gesso sendo esta variação de $5 \mathrm{~kg}$ de gesso e 4,5 1 de água entre $5 \mathrm{~kg}$ de gesso e 51 de água.

\subsection{O Processo Produtivo}

O estudo da cadeia produtiva das fábricas de placas de gesso foi realizado com base nas visitas exploratórias no município, que possibilitaram uma melhor compreensão do fluxo de processos das empresas as diferenças e semelhanças metodológicas e estruturais. A coleta de dados durante a pesquisa de campo se deu através da observação, realização de entrevistas semiestruturadas com funcionários das empresas, registros em caderno de campo e gravações em registros audiovisuais.

Ao final das visitas pode-se destacar que a diferença entre as empresas está diretamente relacionada com o porte de cada uma delas. Empresas de maior demanda possuem, consequentemente, terrenos e construções maiores dedicados à produção, secagem e armazenamento. No que diz respeito à metodologia de produção as diferenças são irrelevantes para a pesquisa uma vez que estão mais relacionadas às pequenas diferenças entre ferramentas e unidades/frascos de medida.

Independentemente de seu porte, as empresas visitadas apresentam necessidades estruturais semelhantes para seu funcionamento que podem ser apresentadas como: armazenamento; produção; secagem e estoque.

O espaço de armazenamento é dedicado à matéria-prima utilizada, gesso e água. Nas empresas de menor porte muitas vezes este espaço fica no mesmo ambiente em que as placas são produzidas. Empresas de maior porte apresentam galpões reservados apenas para a armazenagem do gesso. 
O espaço de produção tem sua estrutura acomodada em galpões cobertos e abrigados da chuva, as construções variam em tamanho e material em acordo com o porte da empresa, durante a pesquisa foram registrados galpões de madeira e de alvenaria. Nos galpões ficam alinhadas bancadas com os moldes das placas e também o espaço de manipulação da água e do gesso para a confecção.

Após a produção as placas precisam passar pelo processo de secagem, que deve ser realizado ao ar livre.

Para melhor organização desta etapa são construídas estruturas de madeira com pequenas coberturas para evitar a incidência direta do sol. Estas estruturas são colocadas em fileiras e distribuídas em uma área externa aos galpões como é possível observar na Figura 1 (a).

Figura 1 - (a) Placas de gesso em processo de secagem e, (b) placas em gesso prontas para serem comercializadas.
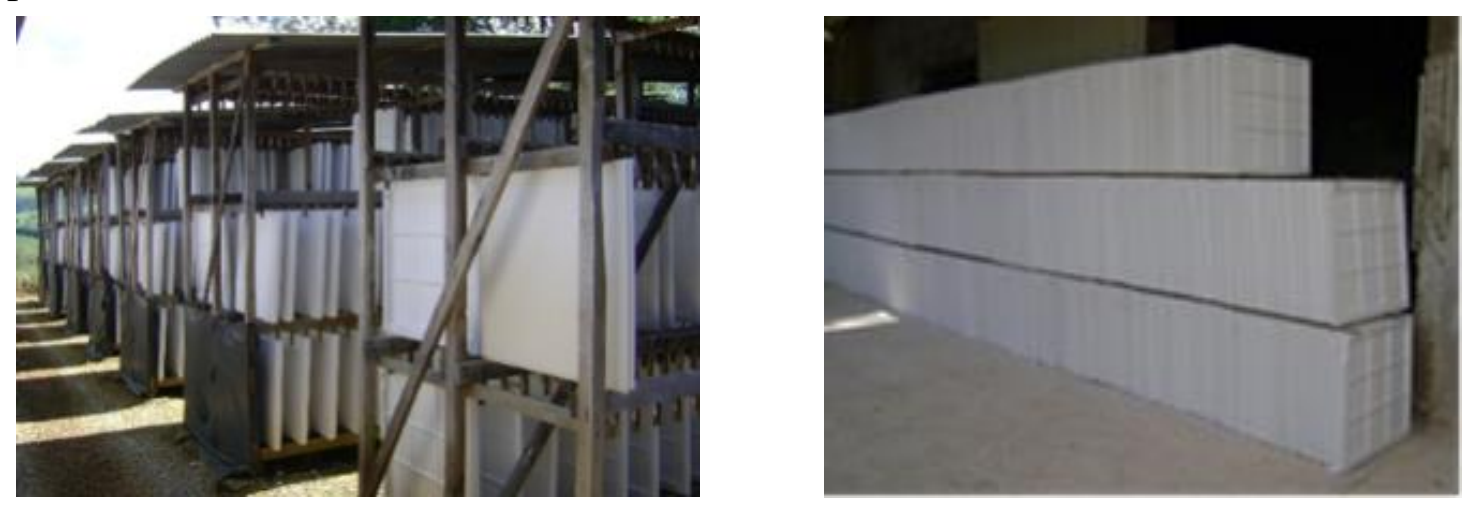

Fonte: Os Autores, 2021.

Depois da secagem as placas são recolhidas e levadas para o estoque, um espaço de armazenamento do produto pronto para o transporte/venda, Figura 1 (b). A maior parte das empresas visitadas trabalha com produção sob demanda portanto este espaço de armazenamento, geralmente, é limitado ao tamanho da produção. Em pequenas empresas os produtos ficam armazenados no mesmo galpão onde acontece a produção.

Produzidas de forma empírica, as placas possuem um processo de feitura cíclico. A primeira etapa consiste na mistura de gesso e água, o fundidor então deposita a matériaprima em um recipiente acoplado a um misturador elétrico. Enquanto a mistura é realizada o fundidor prepara o molde para a peça. O molde das placas é composto por réguas, estruturadas por metalon (tubo de aço carbono), base de vidro e esquadro em cantoneira. Seu preparo consiste na limpeza dos resíduos de gesso da produção anterior, 
no ajuste das cantoneiras e a adição de um lubrificante para evitar que a peça fique presa ao molde.

Concluída esta etapa, a mistura de gesso e água é depositada sobre o molde e o fundidor retoma para a primeira etapa de colocar a matéria-prima no misturador. Quando o último molde é preenchido com a mistura a primeira placa já está pronta para ser retirada do molde e seguir para a secagem e assim o processo pode ser retomado.

A última etapa da produção é a secagem das peças em ambiente externo e é também considerada etapa mais frágil do processo uma vez que depende de condições meteorológicas. Em períodos de chuva a produção precisa ser interrompida porque as placas que não passam pelo processo completo de secagem podem ser danificadas com mofo e, este material não poderá ser reutilizável para a confecção de novas peças.

\section{MATERIAIS E MÉTODOS}

Para que fosse possível chegar a uma relação de proporção ideal de desenvolvimento do compósito foram feitos testes para adequar a relação dos materiais envolvidos (gesso, água e terra de diatomáceas). No fluxograma apresentado na Figura 2 é possível observar que, dois desses processos (b) e (c), a terra de diatomáceas sofreram tratamento térmico antes do desenvolvimento do corpo de prova: a) $\mathrm{O}$ primeiro teste de proporção ocorreu com o material in natura, ou seja, após a coleta do resíduo na cervejaria; b) O segundo teste foi realizado após as terras in natura passarem por um tratamento térmico de $290^{\circ} \mathrm{C}$ durante 4 horas. Esse tratamento foi realizado em um forno de um fogão convencional de cozinha marca ATLAS; c) Para realização do terceiro teste as terras sofreram o tratamento térmico durante 6 horas à $750^{\circ} \mathrm{C}$ em um forno mufla modelo JUNG-LF0212 no Laboratório de Caracterização Estrutural (LCE) da UNIFEI. Esse teste de proporção foi realizado após os resultados obtidos com a análise termogravimétrica (TGA).

Os corpos de prova para teste de proporção foram feitos em moldes de acetato com dimensões de 110 x 25 x 10 mm conforme a norma ASTM C1161-02c.

Figura 2 - Fluxograma apresentando como as amostras foram adquiridas e seus respectivos aspectos visuais. 


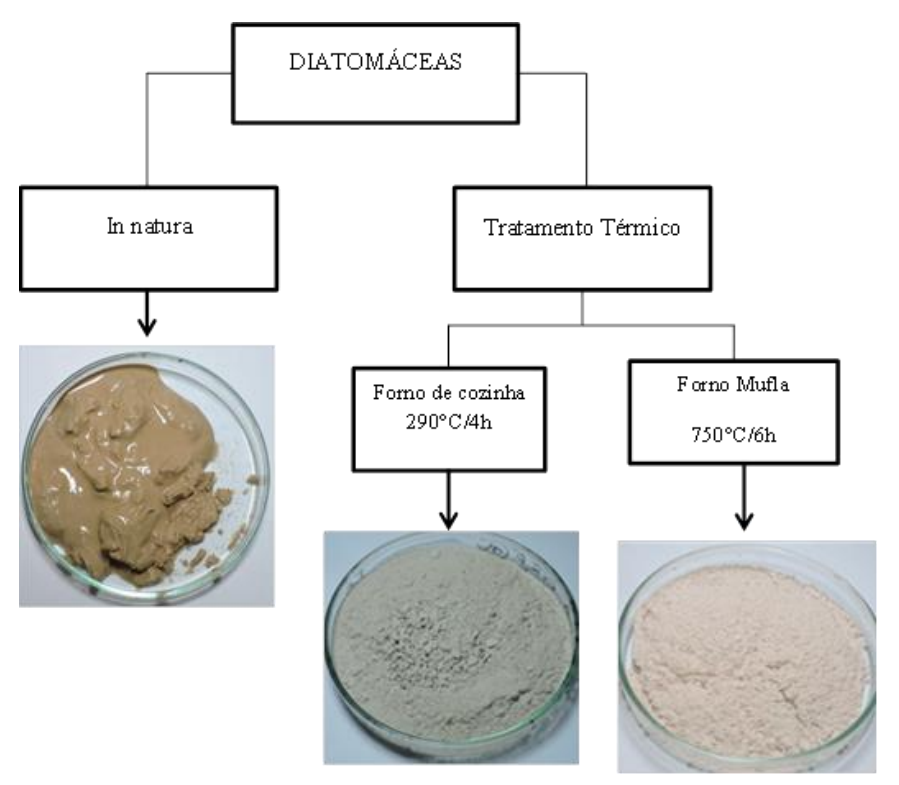

Fonte: Os Autores, 2021.

Diante destes apontamentos, para que a pesquisa fosse executada se fez necessária uma pesquisa exploratória com o intuito de conhecer o território e as ferramentas disponíveis para desenvolvimento e inserção desse novo produto. O material aqui proposto utiliza-se de resíduos da fabricação de cerveja (terra de diatomáceas), Figura 3, Incorporados ao gesso. $\mathrm{O}$ gesso é um material gerado a partir do mineral gipsita sendo composto principalmente por sulfato de cálcio di-hidratado $\left(\mathrm{CaSO}_{4} \cdot 2 \mathrm{H}_{2} \mathrm{O}\right)$.

Figura 3 - Filtro após a clarificação de cerveja, diatomáceas acumuladas.

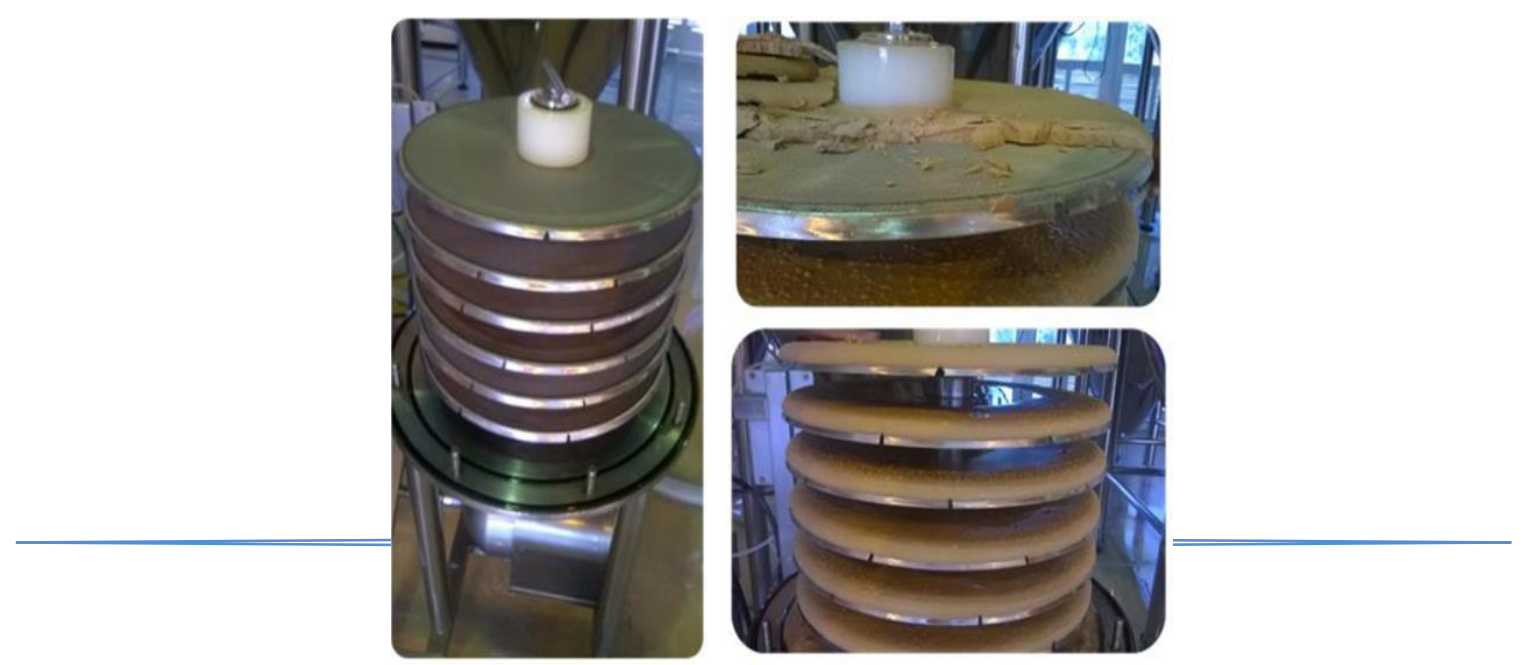


Fonte: Os Autores, 2021.

O material aqui proposto como aditivo ao gesso, as terras de diatomáceas ou diatomita, é uma rocha rica em sílica de origem sedimentar. Diatomáceas são algas unicelulares com vida média de 24 horas e com uma alta capacidade de reprodução, sendo possível um indivíduo originar 100 milhões de descendentes em um período de 30 dias, seus tamanhos variam entre 5 e 400 micra (CIEMIL, 2015; SALIH e GHOSH, 2018).

As visitas exploratórias aconteceram em diferentes fábricas de portes diversificados para que fosse possível compreender o processo produtivo de placas de gesso e as necessidades de cada empresa de acordo com a sua demanda ou estratégia de produção. Após essa exploração foi feita uma investigação de como os funcionários e proprietários das empresas veem esses diferenciais de "implementação". Também durante esta fase inicial de diálogo com os funcionários e proprietários das fábricas foi apresentado o novo material e o descarte da indústria cervejeira para que pudessem se familiarizar para o desenvolvimento de protótipos de placas de gesso.

A motivação para utilização desse resíduo origina-se dessa ausência de descarte adequado para a terra de diatomáceas e a carência de aprimoramentos na produção de artefatos em gesso, a fim de minimizar os impactos ambientais de ambas as partes, tanto na redução da utilização de gesso quanto na reutilização de um material que seria descartado. Evidencia-se também o intuito de inserção desse novo material na cadeia produtiva de empresas familiares de produção de artefatos em gesso.

As questões abordadas direcionam para uma necessidade de intervenção para reutilização deste resíduo de maneira a não interferir agressivamente a cadeia produtiva da empresa que adotar o novo material, promovendo a minimização do impacto ambiental deste descarte e a inovação tecnológica. Então, a pesquisa teve como proposta analisar e compreender a cadeia produtiva e os produtos locais para possível inserção/intervenção que tem por intuito a viabilização de um novo produto e oportunidade de diferencial no mercado. Estas etapas da pesquisa são ambientadas em laboratório técnico institucional e tem por objetivo o desenvolvimento do compósito, que deu origem à pesquisa aqui descrita. Para esse objetivo, faz-se necessário utilizar algumas técnicas para caracterizar o material, sendo essas técnicas mencionadas na Figura 4. Para fabricação dos corpos de prova, foram definidas as proporções de adição de 5 a $15 \%$ (em massa) de terra de 
diatomáceas incorporada ao gesso (sendo estas acrescidas de 5 em 5\%). Estas proporções foram balizadas diante da maior facilidade de adaptação de pequenas empresas à pesagem dos materiais com números inteiros, facilitando a implementação da proposta. Na Figura 4 observa-se como foram preparadas as amostras para cada tipo de análise.

Figura 4 - Fluxograma descritivo sobre como foram preparadas as amostras segundo a necessidade de cada tipo de análise.

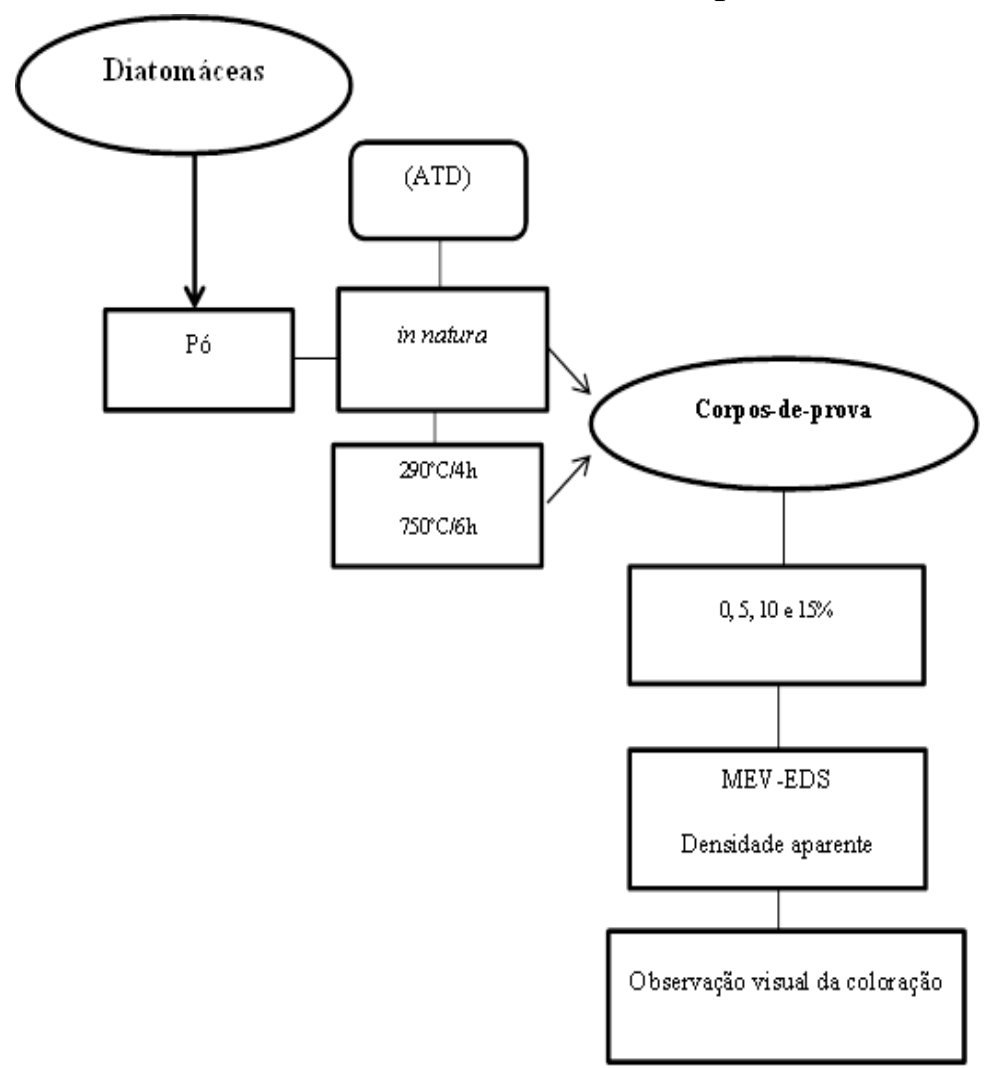

Fonte: Os Autores, 2021.

\section{RESULTADOS E DISCUSSÃO}

A análise termogravimétrica foi realizada no Laboratório de Análise Térmica da UNIFEI com equipamento Mettler TG50. Essa análise foi necessária para visualizar a variável da perda de massa na incidência de calor nas terras de diatomáceas.

Com o resultado obtido foi possível observar três estágios de perda de massa. O primeiro estágio houve uma perda de mais de $50 \%$ a qual está relacionada à eliminação de água fisicamente adsorvida. Entende-se que os dois eventos inicias $\left(26^{\circ} \mathrm{C}\right.$ à $112{ }^{\circ} \mathrm{C} \mathrm{e}$ $139{ }^{\circ} \mathrm{C}$ à $376^{\circ} \mathrm{C}$ ) estão relacionados com eliminação de compostos orgânicos de baixo peso molecular (e água) e o terceiro estágio $\left(403{ }^{\circ} \mathrm{C}\right.$ à $\left.569{ }^{\circ} \mathrm{C}\right)$ está relacionado a eliminação de matéria orgânica mais densa. 
A partir dos resultados obtidos e buscando como referência as análises encontradas em Goulart (2011) e Souza (2003) tem-se que toda matéria orgânica acumulada durante o processo de filtragem e clarificação de cerveja é eliminado em uma temperatura próxima a $600{ }^{\circ} \mathrm{C}$.

O MEV foi realizado nos corpos de prova confeccionados com $0,5,10$ e $15 \%$ de substituição (em massa) pela terra de diatomáceas. Na micrografia do gesso puro, Figura 5, é possível observar a formação de uma estrutura cristalina formada por cristais longos entrelaçados e em formato de agulhas (a) e sem orientação tridimensional em sua distribuição. No ponto (b) é possível observar a formação de uma placa não cristalina densa que sugere a presença de matéria orgânica e no ponto (c) pequenos vazios superficiais.

Figura 5 - Micrografia do gesso puro, sem adição de diatomáceas.

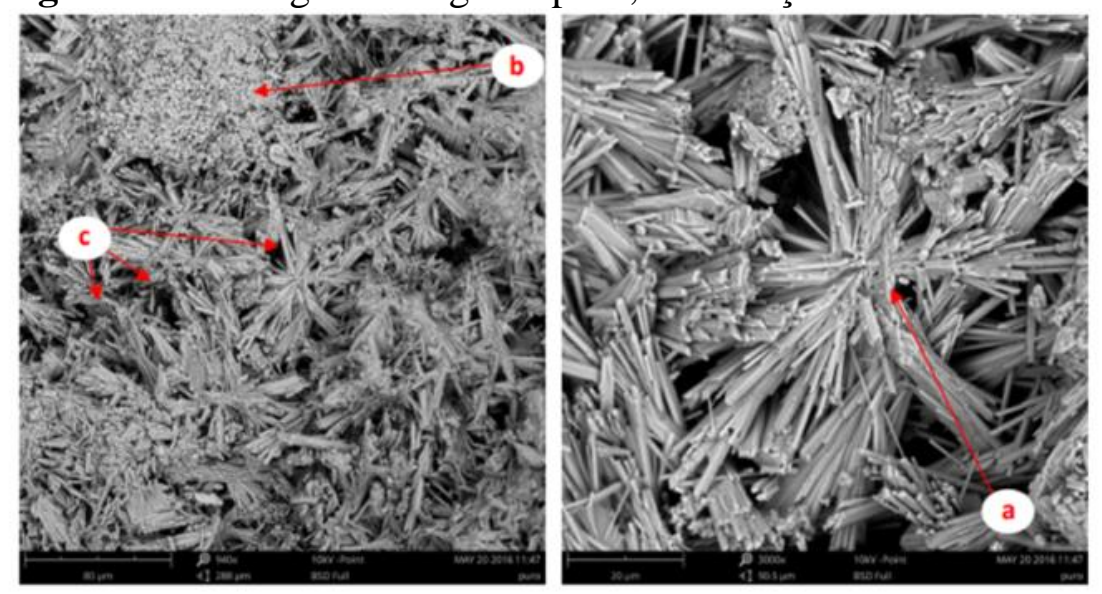

Fonte: Os Autores, 2021.

O MEV foi realizado no corpo de prova com a composição de adição de $5 \%$ de terra de diatomáceas ao gesso no processo de confecção.

$\mathrm{Na}$ micrografia com adição de $5 \%$ de terras ao gesso é possível observar a formação de partículas irregulares, ou seja, a modificação incidente na estrutura cristalina. Os cristais, antes longos, entrelaçados e em formato de agulhas sofrem a quebra da sua estrutura formando aglomerados de cristais não definidos e menores pela interferência das terras (a). A superfície aparenta com mais vazios superficiais (b) do que comparado ao gesso puro, a distribuição e aumento desses vazios pode estar relacionado a não formação completa dos cristais. A Figura 6 (b) compõe a imagem de uma superfície plana do corpo de prova, ou seja, não fraturada. É possível observar, no ponto (c), aglomerados de gesso com partículas de tamanhos uniforme com formação irregular. O ponto (d) é 
composto por uma única partícula de terra de diatomáceas com sua estrutura quase intacta e no ponto (e), pedaços do microorganismo, possivelmente fragmentado durante o processo de filtragem da cerveja.

Figura 6 - Micrografia do gesso com adição de 5\% de terra de diatomáceas.
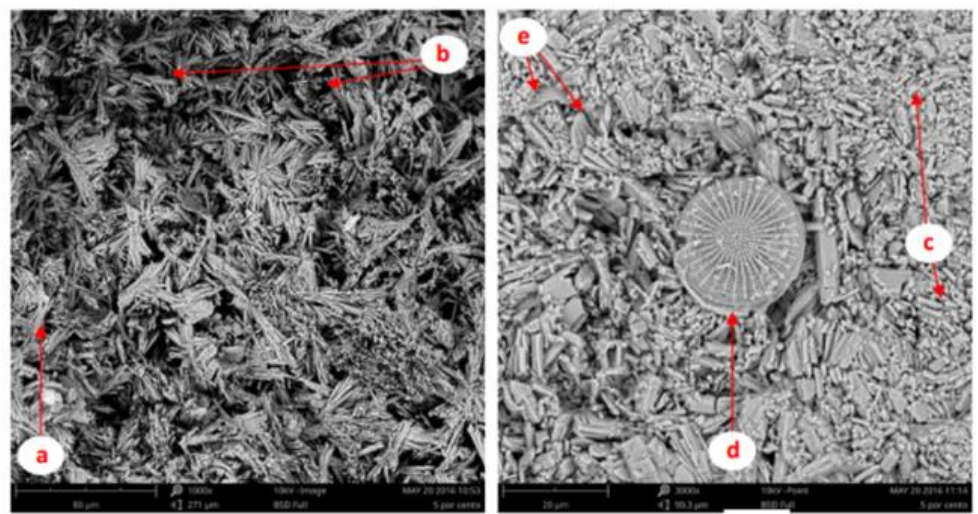

Fonte: Os Autores, 2021

O MEV foi realizado no corpo de prova com a composição de adição de $10 \%$ de terra de diatomáceas ao gesso no processo de confecção. A magnificação da Figura 7 (b) com 10\% de adição foge do padrão de 1000x e 3000x sendo esta com ampliação de 1000x e 5000x respectivamente. Isso se dá devido a falha durante o processo de coleta das imagens que não possibilitou um resultado viável de análise.

$\mathrm{Na}$ micrografia (Figura 7) com adição de $10 \%$ de terras ao gesso é possível observar a não formação de estrutura cristalina com cristais longos e ordenados, sendo as terras responsáveis pela modificação estrutural. No ponto (a) é possível observar a formação de cristais em diferentes tamanhos e a existência da terra de diatomáceas em sua mediação (ponto b). Com o aumento da porcentagem de terras ao gesso é possível notar uma maior atuação das terras no material, sendo estas, responsáveis pela quebra dos cristais.

Figura 7 - Micrografia do gesso com adição de $10 \%$ de terra de diatomáceas.
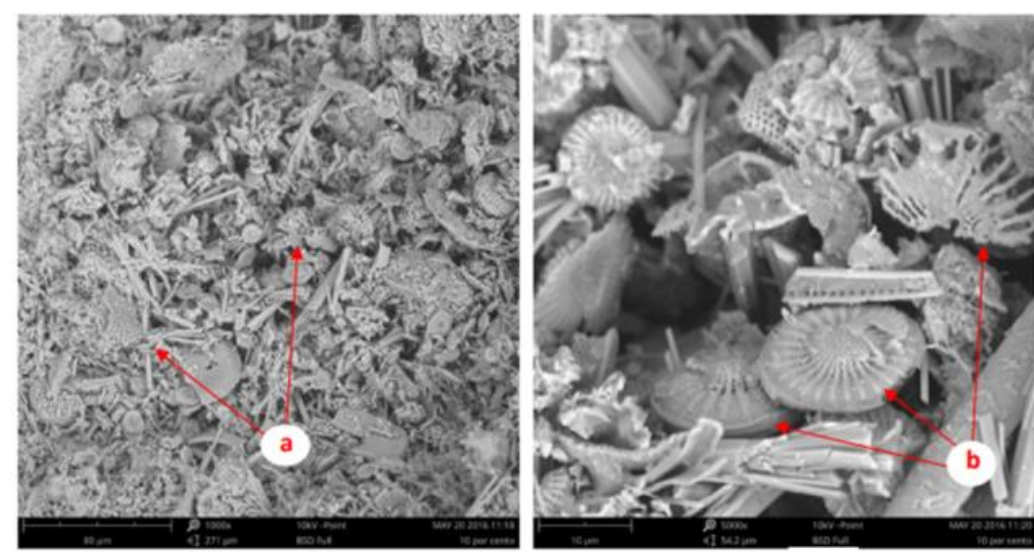

Fonte: Os Autores, 2021. 
O MEV foi realizado no corpo de prova com a composição de adição de $15 \%$ de terra de diatomáceas ao gesso no processo de confecção. Na micrografia apresentada na Figura 8 , com adição de $15 \%$ de terra ao gesso é possível observar a formação de partículas irregulares e a formação de cristais longos entrelaçados (a). Como dito anteriormente o MEV faz uma análise pontual o que sugere que nas análises de 5\% e 10\% a local analisado sofreu uma quebra na formação dos cristais o que possibilita a afirmação de que as terras não são distribuídas uniformemente durante o processo de confecção dos corpos de prova.

Figura 8 - Micrografia do gesso com adição de 15\% de terra de diatomáceas.
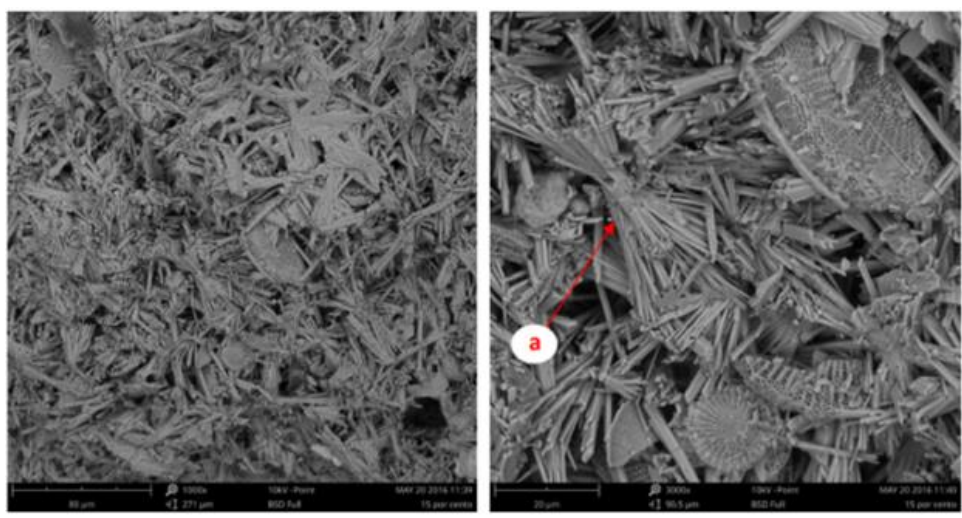

Fonte: Os Autores, 2021

Observando o EDS, no mapeamento da distribuição de elementos químicos que os átomos de Silício estão envoltos (rodeados) por átomos de Oxigênio, o que sugere que além da interação mecânica, também é possível ocorrer uma interação intermolecular ou até mesmo ligações covalentes entre os átomos de Oxigênio (O) e Silício ( $\mathrm{Si}$ ) formando o Óxido de Silício ( $\mathrm{SiO} 2$ ) que ligam entre si na forma de uma rede covalente. Isto sugere a estabilidade e homogeneidade aparente do material. Presume-se que os demais elementos químicos também formam óxidos e são provenientes do gesso, a formação dos mesmos não é prejudicial à interação das terras com o gesso. De acordo com as análises realizadas e as imagens obtidas é possível observar a presença das diatomáceas bem como sua interação mecânica e química no compósito. A Tabela 2 representa a porcentagem de elementos químicos presentes em cada corpo de prova analisado.

Tabela 2 - Espectroscopia por Energia Dispersiva (EDS), quantidade dos elementos químicos presentes em cada amostra. 


\begin{tabular}{c|l|l|l|l|l}
\hline \multicolumn{6}{c}{ Elementos (\% massa) } \\
\hline Amostras & Oxigênio (O) & Cálcio (Ca) & Enxofre (S) & Nitrogênio (N) & Silício (Si) \\
\hline $0 \%$ & 55.5 & 23.1 & 16.8 & 4.6 & 0 \\
$5 \%$ & 59.2 & 18.1 & 13.7 & 5.6 & 3.4 \\
$10 \%$ & 59.9 & 18.8 & 14.9 & 5.1 & 1.3 \\
$15 \%$ & 58.6 & 17.6 & 13.7 & 6.4 & 3.7 \\
\hline
\end{tabular}

Fonte: Os Autores, 2021.

O elemento químico que difere na composição química do gesso e da terra é o Silício, esperava-se uma maior quantidade desse elemento de acordo com o aumento da porcentagem de terra que foi adicionada. No entanto, observa-se uma pequena variação da quantidade de todos os elementos, uma vez que análise realizada é pontual, justificase essa pequena variação. A amostra de $10 \%$ foi a que sofreu a maior variação na quantidade de Silício, sendo isso relacionada à região que foi analisada (Figura 7).

Com os resultados obtidos é possível observar que os problemas encontrados nos corpos de prova a e b são o tempo de secagem após a mistura, ficando acima da média do gesso comum, o que acarretaria em maior tempo de secagem e consequentemente maior tempo de produção até poder ser comercializado. Não afeta a forma de produzir, sim o tempo de secagem. Na Figura 9, podem-se observar corpos-de-prova fabricados com diatomáceas in natura.

Figura 9 - Corpos-de-prova com diatomáceas in natura, da esquerda para a direita, com 5,10 e $15 \%$ respectivamente.

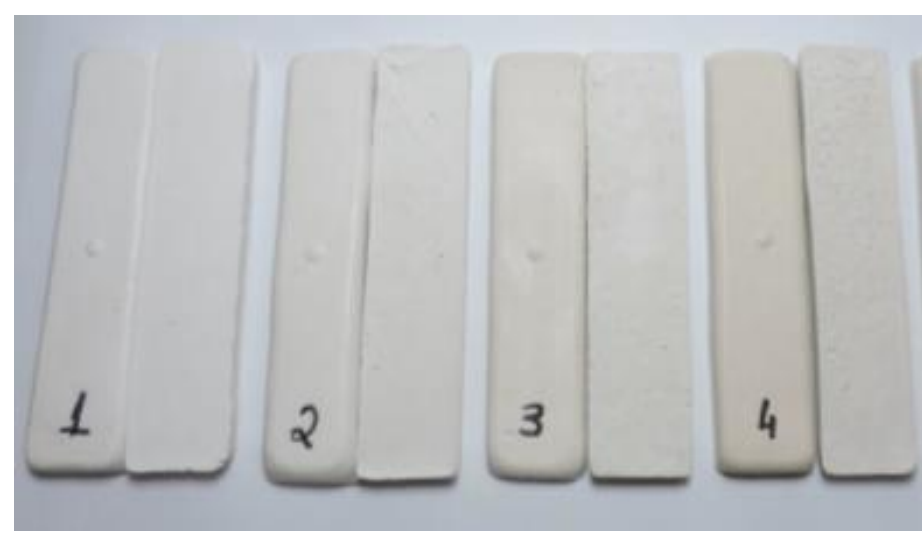

Fonte: Os Autores, 2021.

A coloração do material desenvolvido in natura também interfere no processo de venda, ficando uma coloração marrom. O corpo de prova confeccionado após a secagem da terra de diatomáceas no forno de cozinha convencional tem uma coloração mais clara, 
levemente rosada, um resultado mais próximo do objetivo. A Figura 10 apresenta os corpos-de-prova confeccionados com diatomáceas após tratamento térmico em forno convencional.

Figura 10 - Corpos-de-prova com diatomáceas após tratamento térmico em forno convencional a $290^{\circ} \mathrm{C} / 4 \mathrm{~h}$, da esquerda para a direita, com 5, 10 e $15 \%$ respectivamente.

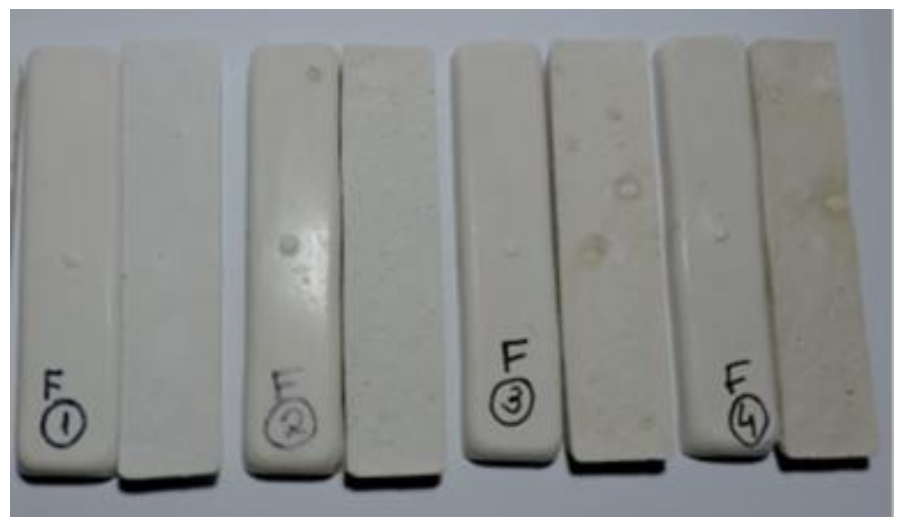

Fonte: Os Autores, 2021.

É notável a diferença nas terras após seu tratamento térmico. Durante o processo térmico o material estufa como um bolo, quando atinge a temperatura em torno de $330{ }^{\circ} \mathrm{C}$ e começa a escurecer e cria uma camada cinza na parte de superior do material. Goulart (2011) afirma que quando as terras em resíduo são submetidas a tratamento térmico durante 6 horas em um forno a $750{ }^{\circ} \mathrm{C}$ a matéria orgânica retida nas terras é eliminada. Subentende-se então que o processo de queima da matéria orgânica adsorvida nas terras se dá nesse período entre $330{ }^{\circ} \mathrm{C}$ até $700{ }^{\circ} \mathrm{C}$ para sua eliminação total. $\mathrm{O}$ material, antes marrom e pastoso se torna um pó rosa e fino.

O corpo de prova que mais se aproximou das características das peças produzidas em gesso foi o que passou por tratamento térmico a $750^{\circ} \mathrm{C} / 6 \mathrm{~h}$ (Figura 11). O tempo de secagem do novo material (gesso e terras diatomáceas) é próximo e em alguns momentos inferior ao que já é utilizado atualmente (gesso e água), promovendo então pouca ou nenhuma alteração para a sua aplicação prática na indústria.

Figura 11 - Corpos-de-prova com diatomáceas após tratamento térmico a $750^{\circ} \mathrm{C} / 6 \mathrm{~h}$, da esquerda para a direita com 0,5 e 10 e $15 \%$ respectivamente. 


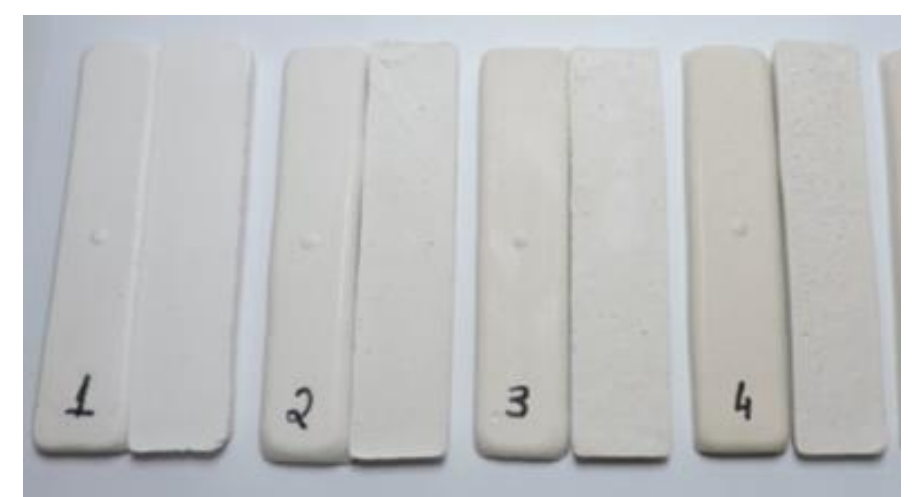

Fonte: Os Autores, 2021.

\section{CONSIDERAÇÕES FINAIS}

Em relação ao impacto ambiental a pesquisa contribui de maneira a minimizar impactos provenientes do descarte inadequado da terra de diatomáceas pela indústria cervejeira e também na redução do consumo de matéria-prima (água e gesso) dentro da empresa que produz as placas de gesso. Podemos então destacar a contribuição ambiental da pesquisa dentro de duas vertentes industriais, tendo início com a possibilidade de reuso de um material orgânico utilizado em grande escala pela indústria cervejeira no país e finalizando com a aplicação em empresas de pequeno porte, promovendo a reciclagem/reutilização da terra de diatomáceas e reduzindo o consumo de água e gesso, recursos naturais não renováveis.

Uma das primeiras preocupações que um empresário deve ter ao pensar a sua empresa é o que ela pode fazer para transformar o mundo ao seu redor de forma positiva, de que maneira ela contribui com a sociedade, o seu impacto social. Talvez, na prática, esta preocupação não seja uma presença marcante na totalidade do cenário empresarial a pesquisa realizada então carrega consigo alguns aspectos que são considerados viáveis para a contribuição social da empresa com o local de atuação no qual ela está inserida.

Destacam-se então questões como a capacitação de mão-de-obra para a preparação e manuseio do novo material, produção de manuais técnicos para uso dos trabalhadores e a promoção do desenvolvimento regional que segue desde a melhoria das condições de trabalho e aptidões dos funcionários até o levantamento de questionamentos sobre novos investimentos e preocupações ambientais dentro das empresas concorrentes e consequente busca por novos valores para seus produtos.

Quando tomamos por perspectiva o impacto econômico da pesquisa desenvolvida ganha destaque a redução do custo do produto e no processo de produção da fábrica de 
placas de gesso. Esta diminuição do custo de produção das placas acarreta em melhorias diretas e indiretas no faturamento da empresa. Com o uso do novo material e a consequente redução do uso de gesso e água já é possível registrar o aumento do lucro da empresa sem necessariamente aumentar o volume de vendas ou o valor do produto no mercado.

Destaca-se também outra possibilidade de atuação para promover um maior faturamento das empresas que adotarem este novo compósito para a produção de outras peças em gesso. A realização de estudos de comunicação e marketing para a divulgação da nova postura da empresa, que pratica o reuso de resíduo em sua produção, é um caminho para promover uma maior conscientização de seus clientes sobre os valores sociais e ambientais que são agregados em seus produtos. Com um maior valor agregado os produtos ganham também mais espaço para uma maior valorização monetária no mercado.

Na presente pesquisa destaca-se seu caráter inovador a partir do reuso da terra de diatomáceas, uma vez que seu uso já se faz comum não só na indústria cervejeira. Suas propriedades filtrantes a colocam nos processos de clarificação e classificação de açúcar, suco de frutas, bebidas alcoólicas, ácidos, compostos de petróleos, vernizes, ceras, graxas, resinas, tintas, óleos vegetais, minerais e animais. Seu potencial como isolante térmico é utilizado na construção de caldeiras, fornos, condutores, som e temperatura em forma de tijolos ou pó. Na indústria farmacêutica é utilizada para filtrar xaropes, produção de pomadas dermatológicas e pastas de dentes. Também pode ser encontrada em inseticidas, fungicidas, pilhas elétricas e na construção civil.

Como proposto, a pesquisa percorreu então o universo das empresas produtoras de placas moldadas de gesso em Conceição dos Ouros e também foi explorada dentro dos laboratórios acadêmicos preservando o seu caráter interdisciplinar que une o Design, a Engenharia e as Ciências Sociais para o estudo da possibilidade de inserção de um novo material na cadeia produtiva das empresas com a menor interferência possível dentro desta cadeia.

A pesquisa constatou então que a dificuldade de inserção do material não está ligada à técnica e sim à estrutura da indústria do gesso e sua construção social. A implementação do novo material na cadeia produtiva das empresas implica não apenas o seu uso, mas também o estabelecimento de novas negociações para a empresa produtora. Inicialmente a empresa precisa estabelecer contato com a empresa que produz o resíduo 
para garantir a sua matéria-prima e só então segue para a mudança da relação com o seu público, seus compradores, para apresentar o novo conceito associado ao produto.

A indústria do gesso na cidade é composta, em sua maioria, por empresas que estão há gerações sob o cuidado de uma mesma família e conhecimentos técnicos/modos de fazer transmitidos dos mais velhos para os mais novos, estabelecendo uma tradição e padrões que criam barreiras para a entrada da inovação.

Mesmo com algumas automatizações no processo, como máquinas que auxiliam na mistura do gesso, o caráter familiar e manual/artesanal ainda tem forte presença nas grandes e pequenas empresas que trabalham com o gesso em Conceição dos Ouros. Este cenário de produção e mercado já estabelecidos e que, diferente de outros setores industriais, não é movido pela necessidade de constante inovação e atualização, da tradição, que preserva os modos de fazer, acaba por se tornar também um dificultador da inserção de um novo material. Os proprietários das empresas se mostram satisfeitos com a estrutura de suas empresas e não demonstram interesse em alterar seus processos de produção e fugir dos padrões convencionais de produção e negociação. Entendem que seus produtos atendem a demanda do mercado, possuem um baixo custo de produção e isto lhes parece suficiente.

\section{REFERÊNCIAS}

ASHBY, M. F.; JOHNSON, K. Materiais e Design: arte e ciência da seleção de materiais no design de produtos. Brasil: Elsevier, $2^{\circ}$ Edição, 2013.

Associação Brasileira da Indústria da Cerveja. Disponível em: $<$ http://cervbrasil.org.br/>. Acesso em: 10 jul. 2021.

BACK N, OGLIARI A, DIAS A. \& SILVA JC. Projeto Integrado de Produtos. Manole, Barueri, SP, 2008.

BARTON JA, LOVE DM, TAYLOR GD. Design determines 70\% of cost? A review of implications for design evaluation. Journal of Engineering Design, 12:1, pp 47-58, 2001. Disponível em: https://doi.org/10.1080/09544820010031553. Acesso em: 02 ago. 2021.

BAXTER M. Projeto de Produto: Guia prático para o desenvolvimento de novos Produtos. Edgar Blücher, São Paulo, 1998. 
BAXTER, M. Projeto de Produtos - Guia Prático para o Design de Novos

Produtos. 3 ed. 344 p. Editora Blücher. ISBN: 9788521266149. 2011.

BONSIEPE, G. Design como prática do projeto. Blucher, 2012.

CALLISTER, W. D.; Ciência Engenharia de Materiais: Uma Introdução. LTC, São Paulo, 8 Edição, 2012.

CIEMIL. Comércio, Indústria e Exportação de Minérios Ltda. Disponível em:

<http://www.ciemil.com.br/interface/index_diatomita.html >. Acesso em: 03 ago. 2021.

COUTO, R. M. S. (org). Forma do Design: por uma metodologia interdisciplinar. Editora Rio Books: Rio de Janeiro, 2014.

DAMAZIO, V. M. M. Artefatos de Memória da Vida Cotidiana: um olhar interdisciplinar sobre as coisas que fazem bem lembrar. Tese de doutorado. Universidade do Estado do Rio de Janeiro. Instituto de Filosofia e Ciências Humanas. Programa de Pós-Graduação em Ciências Sociais. Rio de Janeiro, 2005. 285p. Disponível em: http://www.pucrio.br/pibic/relatorio_resumo2012/relatorios_pdf/ctch/ART/DAD-

Gabriel\%20Franklin\%20e\%20Vincer\%20Victor.pdf. Acesso em: 26 jul. 2021.

Departamento de Produção Mineral - DNPM. Em sumário mineral 2013. Disponível em: <http://www.dnpm.gov.br/>. Acesso em: 05 ago. 2021.

DOSSE, F. O império do sentido: a humanização das ciências humanas. Ilka Stern Cohen (trad.), Bauru, SP: EDUSC, 2003.

Instituto Brasileiro de Geografia e Estatística. Disponível em: <https://www.ibge.gov.br/>. Acesso em: 15 out. 2021.

JAPIASSU, H. A questão da interdisciplinaridade. SEMINÁRIO INTERNACIONAL SOBRE REESTRUTURAÇÃO CURRICULAR. Secretaria Municipal de Educação, Porto Alegre, 1994.

KINDLEIN Jr., W.; GUANABARA, A. S. A importância do Binômio Design e Engenharia como Catalisador de Inovação. Curitiba: Anais $7^{\circ} \mathrm{P} \& \mathrm{D}$ Design Congresso Brasileiro e Pesquisa e Desenvolvimento em Design, 2006. 10p.

KRUCKEN, L. Design e território: valorização de identidades e produtos locais. São Paulo: Nobel, 2009.

LATOUR, B. Reagregando o social: uma introdução à Teoria do Ator-Rede. Salvador: Ed. UFBA, 2012.

LATOUR, B.; WOOLGAR, S. A vida de laboratório: a produção dos fatos científicos. Rio de Janeiro: Relume Dumará, 1997. 
LAW, J. Notes on the theory of the actor-network: ordering, strategy, and heterogeneity. Plenum Publishing Corporation, Systems Practice, Vol. 5, No. 4, 1992.

LÖBACH, B. Design Industrial: bases para a configuração dos produtos industriais. São Paulo: Editora Edgard Blücher, 2001.

MEYER, G. C. O. Design-Rede: repensando os interesses do design. Estudos em Design, v. 19, n. 1, 2015.

MUNFORD, E. The Story of socio-technical Design: Reflections on its Success, Failures and Potencial. Information Systems Journal 16 (4): 317 - 342, 2006.

Disponível em: DOI: 101111/j.1365-2575-2006.00221.x. Acesso em: 10 jul. 2021.

Prefeitura Municipal de Conceição dos Ouros, MG. Disponível em:

https://www.conceicaodosouros.mg.gov.br/historia-de-conceicao-dos-ouros. Acesso em: 15 out. 2021.

RAYNAUT, C. Interdisciplinaridade: mundo contemporâneo, complexidade e desafios à produção e à aplicação de conhecimentos. PHLIPPI JR Alindo \& NETO, Antonio J. Silva. THOMAS, H.; BUCH, A. (Coord.). Actos, actores y artefactos: sociologia de la tecnologia. $1^{\mathrm{a}} \mathrm{Ed}, 1^{\mathrm{a}}$ Reimpressão - Bernal: Universidad Nacional de Quilmes, 2013.

SALIH, S. S.; GHOSH, T. K. International Journal of Biological Macromolecules Adsorption of Zn ( II ) ions by chitosan coated diatomaceous earth. International Journal of Biological Macromolecules, v. 106, p. 602-610, 2018. Disponível em: https://doi.org/10.1016/j.ijbiomac.2017.08.053. Acesso em: 20 ago. 2021.

VALADÃO, J. A. D.; ANDRADE, J. A. Entre os Sistemas Sociotécnicos e os Conjuntos Sociotécnicos: Tecnologia Social como Mediação Sociotécnica. XXXVI Encontro da ANPAD, Rio de Janeiro, 2012. Disponível em: http://www.anpad.org.br/diversos/down_zips/63/2012_GCT391.pdf. Acesso em: 17 ago. 2021.

VARGENS, J. M. C. Uma abordagem sociotécnica para design e desenvolvimento de sistemas de informação em saúde no âmbito do SUS. Tese de doutorado. Fundação Oswaldo Cruz. Instituto de Comunicação e Informação Científica e Tecnológica. Rio de Janeiro, 2014. 227p. Disponível em: https://www.arca.fiocruz.br/bitstream/icict/12976/1/ve_Jos\%c3\%a9_Muniz_ENSP_201 4. Acesso em: 10 ago. 2021. 